\title{
Efeito da luz e da Quebra de Dormência na Germinação de Sementes de Espécies de Plantas Daninhas ${ }^{1}$
}

\author{
Effect of Light and Dormancy Break on Weed Species Seed Germination
}

\author{
SALVADOR, F.L. ${ }^{2}$, VICTORIA FILHO, R. ${ }^{3}$, ALVES, A.S.R. ${ }^{2}$, SIMONI, F. ${ }^{2}$ e SAN MARTIN, H.A.M. ${ }^{2}$
}

\begin{abstract}
RESUMO - Objetivou-se com este trabalho verificar a quebra de dormência, utilizando ácido sulfúrico $\left(\mathrm{H}_{2} \mathrm{SO}_{4}\right)$ e escarificação mecânica, e o efeito da luz na germinação das espécies Euphorbia heterophylla, Ipomoea nil, Sida glaziovii e Brachiaria plantaginea. Para avaliar a germinação, os tratamentos foram realizados no escuro e no claro. Não foram constatadas diferenças entre eles nas condições avaliadas, indicando que as espécies em estudo germinam em ambiente com diferentes luminosidades. Quanto a quebra de dormência, observou-se que o tratamento submetido à quebra de dormência aumentou a porcentagem de germinação em algumas espécies. Desse modo, concluiu-se que a quebra de dormência viabiliza condições para germinação de algumas espécies de plantas daninhas e, sob qualquer condição de luminosidade, há germinação das sementes das espécies estudadas.
\end{abstract}

Palavras-chave: germinação, luminosidade, planta daninha, dormência.

\begin{abstract}
This research evaluated dormancy break using sulfuric acid $\left(\mathrm{H}_{2} \mathrm{SO}_{4}\right)$, mechanical scarification and the effect of light on the seed germination rate of Euphorbia heterophylla, Ipomoea nil, Sida glaziovii and Brachiaria plantaginea. To evaluate the germination rate, treatments were performed in the dark and light; no differences were observed between both treatments under these conditions, indicating that these species germinate under different light conditions. Dormancy break increases the percentage of germination rate in some species. Thus, dormancy break makes the germination of some species viable. The germination can occur both under light or dark conditions.
\end{abstract}

Keywords: germination, luminosity, weed, dormancy.

\section{INTRODUÇÃO}

Dormência é o fenômeno no qual as sementes de uma determinada espécie, mesmo sendo viáveis e tendo condições ambientais para tanto, não germinam (Carvalho \& Nakagawa, 1983). A dormência é um mecanismo de defesa das sementes contra as variações do ambiente, as quais dificultam ou impedem sua atividade metabólica normal (Marcos Filho, 2005).

Segundo Egley (1995) a dormência é a incapacidade do embrião reassumir o nível de crescimento necessário para a emissão da raiz primária, mesmo na ausência de fatores de inibição e na presença de condições ambientais favoráveis à germinação.

A dormência é um recurso eficaz para a preservação da continuidade da espécie, pois constitui um mecanismo de resistência as condições desfavoráveis do ambiente (Bewley, 1997). As plantas daninhas, em especial, dependem diretamente da germinação para infestar e competir com as espécies cultivadas (Roberts, 1999); deste modo, a promoção da germinação das espécies invasoras pode ser

\footnotetext{
1 Recebido para publicação em 18.7.2006 e na forma revisada em 15.5.2007.

2 Pós-graduandos em Fitotecnia da ESALQ/USP, Av. Pádua Dias, 11 Caixa Postal 9, 13418-900, Piracicaba-SP, $<$ fernandalopes_salvador@yahoo.com.br>; ${ }^{3}$ Eng ${ }^{2}$-Agr ${ }^{\circ}$, Dr. Professor da ESALQ/USP, <rvictori@esalq.usp.br>.
} 
afetada por condições de luz, temperatura, ação de fitormônios e umidade, que são variáveis durante o período de formação das sementes (Takahoshi, 1995).

A luz está ligada à ativação do sistema de fitocromos, o qual está relacionado ao funcionamento das membranas celulares; podendo ocasionar uma alteração no fluxo de inúmeras substâncias nas células e de permeabilidade das membranas, contribuindo para quebrar a dormência (Hilhorst \& Karssen, 1988).

Gallagher \& Cardina $(1997,1998)$ e Letchamo \& Gosselin (1996) constataram que a luz não apenas consegue quebrar a dormência e promover a germinação de outras espécies, como também provoca inibição em algumas delas. Fleck et al. (2001) observaram que a luz é importante para promover a germinação de Bidens pilosa; entretanto, para Sida rhombifolia a luz não é essencial para a germinação de suas sementes. Desse modo, B. pilosa é classificada como planta sensivel à luz, e S. glaziovii, como insensivel.

Há duas causas básicas de dormência: a imposta pelo tegumento e a dormência primária. A primeira envolve a interferência na absorção de água, nas trocas gasosas, a presença de inibidores, como a cumarina, ácido abscísico e a prevenção à saída dos mesmos presentes no embrião; já a segunda envolve o balanço entre substâncias inibidoras e promotoras da germinação, como os fitormônios (Bewley \& Black, 1994).

Em relação à superação de dormência, vários métodos foram testados, como, por exemplo, a imersão de sementes de Ipomoea hederifoli, Ipomoea quamoclit e Ipomoea grandifolia em ácido sulfúrico de 5 a 20 minutos, resultando em aumento na porcentagem de germinação de 76,43 e 58\%, respectivamente (Azania et al., 2003). Segundo Ogunwenmo \& Ugborogho (1999), a escarificação mecânica (corte ou perfuração do tegumento) das sementes de Ipomoea obscura, I. hederifolia e I. involucrata foi eficiente para aumentar a porcentagem de germinação das espécies.

Freitas et al. (1990) testaram diferentes métodos de quebra de dormência para sementes de $B$. plantaginea e verificaram que a imersão em ácido sulfúrico concentrado de 15 a 60 minutos foi suficiente para escarificar o tegumento e permitir a germinação.

Devido à diversidade dos estados de dormência à variabilidade de respostas germinativas das sementes, é dificil a previsão das infestações da cultura, tornando-se indispensável o conhecimento dos processos responsáveis pela germinação das plantas daninhas (Freitas, 1990). Assim, objetivou-se com este trabalho avaliar a germinação de quatro espécies de plantas daninhas, na presença e ausência de luz, submetidas a tratamento de quebra de dormência.

\section{MATERIAL E MÉTODOS}

O experimento foi realizado no Laboratório de Análise de Sementes do Departamento de Produção Vegetal da Escola Superior de Agricultura Luiz de Queiroz/Universidade de São Paulo, Piracicaba - SP, utilizando sementes de amendoim-bravo (E. heterophylla), corda-deviola (I. nil), guanxuma (S. glaziovii) e capimmarmelada (B. plantaginea).

Após dois meses da colheita das sementes no campo, elas, livres de impurezas, passaram, como método de superação de dormência, por tratamento químico (ácido sulfúrico) e mecânico (escarificação mecânica). Os dois tratamentos foram realizados para todas as espécies estudadas e após testes preliminares determinou-se o melhor método para cada uma.

Após os testes preliminares, constatou-se que as sementes de $I$. nil e E. heterophylla conseguiram germinar utilizando como método de superação de dormência uma escarificação mecânica, que foi realizada com o auxílio de duas lixas de parede (número 2). As sementes foram colocadas entre as duas lixas e friccionadas por um minuto até a abrasão dos tegumentos, mas sem injuriá-los. Este tipo de método de superação de dormência (escarificação) geralmente é usado nas espécies que apresentam as sementes dormentes devido à impermeabilidade do tegumento à água, que foi o caso de I. nil e E. heterophylla.

As sementes de $S$. glazioviie B. plantaginea apresentaram dormência relacionada à impermeabilidade do tegumento à água e também algum outro tipo de dormência, que pode 
ser resistência mecânica do tegumento, impermeabilidade do tegumento a trocas gasosas ou até mesmo uma combinação de causas de dormência, as quais não puderam ser analisadas individualmente neste trabalho. Desse modo, houve necessidade da utilização de uma escarificação química - que foi realizada com o auxílio do ácido sulfúrico PA (duas partes de ácido para uma de semente, em volume) como método de superação de dormência para as referidas espécies. As sementes dessas espécies foram mantidas em contato com essa solução por 10 minutos; em seguida, o ácido foi escorrido e as sementes colocadas em um recipiente com água, para eliminação do excesso do produto, sendo secas à temperatura ambiente para posterior semeadura (Cícero, 1986).

\section{Teste de germinação e velocidade de germinação}

Após o tratamento de quebra de dormência, realizou-se o teste de germinação, que foi baseado nas instruções gerais contidas nas Regras para Análise de Sementes (Brasil, 1992), com quatro repetições de 50 sementes cada. As sementes foram semeadas sobre duas folhas de papel "germiteste", dispostas no interior de caixas de plástico (11 x 11 x $3 \mathrm{~cm})$ transparentes e pretas e umedecidas com quantidade de água destilada equivalente a 2,5 vezes o peso do papel.

Os tratamentos luz e escuro foram caracterizados pelas caixas de plástico transparentes, as quais permitiam a passagem de luz, caracterizando o tratamento luz; e pelas caixas de plástico pretas, que impediam a passagem de luz, caracterizando o tratamento escuro.

As caixas foram mantidas em germinador à temperatura alternada de $20^{\circ} \mathrm{C}$ e $30^{\circ} \mathrm{C}$, sendo 16 horas a $20^{\circ} \mathrm{C}$ com as lâmpadas do germinador apagadas e 8 horas a $30^{\circ} \mathrm{C}$ com as lâmpadas acesas (Brasil, 1992).

O delineamento experimental utilizado foi o de blocos ao acaso no esquema fatorial $2 \times 4 \times 2$, com quatro repetições. Os tratamentos foram conseqüência da combinação fatorial entre dois niveis de dormência (com e sem quebra de dormência), quatro espécies de plantas daninhas e dois niveis de intensidade luminosa (com e sem luz). Os dados foram submetidos à análise de variância, em esquema fatorial $2 \times 4 \times 2$, com aplicação do teste F. Em seguida, aplicou-se o teste de Tukey a 5\%, para comparação de médias.

\section{Avaliações}

A germinação foi avaliada segundo dois aspectos: o percentual e o índice de velocidade de germinação (IVG) utilizando a fórmula proposta por Maguire (1962), como segue: $\mathrm{IVG}=$ $[\mathrm{N} 1 / 1+\mathrm{N} 2 / 2+\mathrm{N} 3 / 3+\ldots+\mathrm{Nn} / \mathrm{n}]$, em que N1, N2, N3 e Nn são as porcentagens de sementes germinadas no primeiro, segundo, terceiro e enésimo dias após a semeadura. A porcentagem de plântulas normais foi computada diariamente (Brasil, 1992), considerando-se semente germinada aquela em que ocorreu a emissão da radícula e da parte aérea, durante 30 dias.

A observação da germinação das caixas plásticas pretas foi feita sob luz verde de segurança (Noronha et al., 1978). Os dados foram submetidos à análise de variância e comparados pelas médias através do teste de Tukey a $5 \%$.

\section{RESULTADOS E DISCUSSÃO}

Na Tabela 1 encontram-se os valores da análise de variância do índice de velocidade de germinação (IVG) e da porcentagem de germinação. A única interação significativa a 5\% de probabilidade pelo teste $\mathrm{F}$ foi tratamento $\mathrm{x}$ espécie.

O desdobramento da interação tratamento $\mathrm{x}$ espécie pode ser observado na Tabela 2 . Em relação ao IVG, a espécie $I$. nil apresentou melhor indice no tratamento com quebra de dormência, aumentando o indice de 4,72 no tratamento sem quebra para 6,41 no tratamento com quebra de dormência. S. glazioviiaumentou o IVG de 0,13 para 1,58 no tratamento sem quebra e com quebra, respectivamente, o que significou que o último tratamento proporcionou à semente uma germinação mais rápida, devido à retirada do tegumento que impedia a germinação. Dessa forma, houve aumento no IVG com o tratamento de superação de dormência.

Planta Daninha, Viçosa-MG v. 25, n. 2, p. 303-308, 2007 
Tabela 1 - Quadrado médio e valores de F para os componentes da análise de variância do IVG e da germinação

\begin{tabular}{|c|c|c|c|c|c|}
\hline \multirow{2}{*}{ Fonte de variação } & \multirow{2}{*}{ GL } & \multicolumn{2}{|c|}{ QM } & \multicolumn{2}{|c|}{$\mathrm{F}$} \\
\hline & & IVG & Germinação & IVG & Germinação \\
\hline Quebra de dormência & 1 & 14,809 & 4096,000 & $38,41^{*}$ & $73,99^{* *}$ \\
\hline Bloco & 6 & 0,490 & 57,833 & $1,27^{*}$ & $1,04^{* *}$ \\
\hline Espécie & 3 & 98,383 & 9808,667 & $255,19^{* *}$ & $177,19^{* *}$ \\
\hline Luminosidade & 1 & 2,177 & 49,000 & $5,65^{*}$ & $0,89^{\mathrm{ns}}$ \\
\hline Quebra de dormência x espécie & 3 & 9,606 & 373,667 & $24,92^{* *}$ & $6,75^{* *}$ \\
\hline Quebra de dormência $x$ luminosidade & 1 & 0,331 & 0,00001 & $0,86^{\mathrm{ns}}$ & $0,0000002^{\text {ns }}$ \\
\hline Espécie $\mathrm{x}$ luminosidade & 3 & 0,936 & 24,667 & $2,43^{\mathrm{ns}}$ & $0,45^{\mathrm{ns}}$ \\
\hline Quebra de dormência x esp. x luminosidade & 3 & 0,469 & 32,333 & $1,22^{\mathrm{ns}}$ & $0,58^{\mathrm{ns}}$ \\
\hline Resíduo & 42 & 0,385 & 55,357 & - & - \\
\hline Total & 63 & & & & \\
\hline
\end{tabular}

$* *$ significativo a $1 \%$ de probabilidade; * significativo a $5 \%$ de probabilidade.

Para a espécie $B$. plantaginea, o indice passou de 1,30 no tratamento sem quebra para 3,35 no tratamento com quebra (Tabela 2). A única espécie que apresentou declínio no îndice de velocidade de germinação com o tratamento quebra de dormência foi $E$. heterophylla. Possivelmente esta espécie apresenta maior permeabilidade da membrana quando comparada com as outras; e a quebra de dormência pode ter ocasionado efeito inverso: em vez de facilitar a entrada de água nas sementes, causou algum dano por embebição no embrião, o que ocasionou redução no índice de velocidade de germinação.

Em geral, o tratamento quebra de dormência proporcionou melhoria no IVG, exceto para E. heterophylla. As espécies apresentaram incremento no índice após os tratamentos de superação de dormência (Tabela 2), o que está relacionado com uma rápida absorção de água e, conseqüentemente, uma maior germinação.

O desdobramento da interação tratamento $\mathrm{x}$ espécie em relação à porcentagem de germinação pode ser observado na Tabela 3. Verificaram-se diferenças estatísticas na porcentagem de germinação das sementes de plantas daninhas, exceto para E. heterophylla. Em relação a $I$. nil, verificou-se que no tratamento sem quebra de dormência a germinação foi de $47,25 \%$ contra $71,50 \%$ quando se utilizou a escarificação como método de superação de dormência, representando incremento de 51,32\% na germinação de $I$. nil. A espécie que apresentou a maior diferença, comparando-se os dois tratamentos (com e sem quebra), utilizando o ácido sulfúrico foi $S$. glaziovii, que aumentou sua porcentagem de germinação de $2,75 \%$ para 19,50\% (Tabela 3).

Quanto a B. plantaginea, com o tratamento quebra de dormência, a germinação passou de $24,50 \%$ (sem quebra) para 45,25\% (com quebra), representando incremento de $84,69 \%$ (Tabela 3).

No tocante à interação tratamento x luminosidade, não houve diferença estatística entre as espécies ao comparar os tratamentos com quebra de dormência e sem quebra; todas obtiveram resultados semelhantes de germinação tanto na luz quanto no escuro. Esse comportamento demonstrou que as sementes dessas espécies podem ser classificadas como indiferentes em relação à preferência pela luz. Esses resultados discordam dos encontrados por Felippe \& Polo (1983), os quais constataram que $S$. glaziovii apresentou germinação fotoblástica negativa. O tempo de armazenamento das sementes testadas pelos referidos autores 
Tabela 2 - Índice de velocidade de germinação de sementes de plantas daninhas submetidas ao tratamento sem quebra de dormência e com quebra de dormência mecânica, para E. heterophylla e I. nil, e com quebra de dormência química, para S. glaziovii e B. plantaginea

\begin{tabular}{|l|c|c|c|c|}
\hline \multirow{2}{*}{ Tratamento } & \multicolumn{4}{|c|}{ Espécies } \\
\cline { 2 - 5 } & E. heterophylla & I. nil & S. glaziovii & B. plantaginea \\
\hline Sem quebra & $6,60 \mathrm{a}$ & $4,72 \mathrm{~b}$ & $0,13 \mathrm{~b}$ & $1,30 \mathrm{~b}$ \\
\hline Com quebra & $5,26 \mathrm{~b}$ & $6,41 \mathrm{a}$ & $1,58 \mathrm{a}$ & $3,35 \mathrm{a}$ \\
\hline
\end{tabular}

* Letras iguais nas colunas não diferem entre si pelo teste de Tukey a $5 \%$.

Tabela 3 - Porcentagem de germinação de sementes de plantas daninhas submetidas ao tratamento sem quebra de dormência e com quebra de dormência mecânica, para E. heterophylla e $I$. nil, e com quebra de dormência química, para S. glaziovii e B. plantaginea

\begin{tabular}{|l|c|c|c|c|}
\hline \multirow{2}{*}{ Tratamento } & \multicolumn{4}{|c|}{ Espécies } \\
\cline { 2 - 5 } & E. heterophylla & I. nil & S. glaziovii & B. plantaginea \\
\hline Sem quebra & $64,00 \mathrm{a}$ & $47,25 \mathrm{~b}$ & $2,75 \mathrm{~b}$ & $24,50 \mathrm{~b}$ \\
\hline Com quebra & $66,25 \mathrm{a}$ & $71,50 \mathrm{a}$ & $19,50 \mathrm{a}$ & $45,25 \mathrm{a}$ \\
\hline
\end{tabular}

* Letras iguais nas colunas não diferem entre si pelo teste de Tukey a 5\%.

(sete meses) pode ter influenciado o resultado do fotoblastismo desta espécie, discordando dos resultados obtidos nesta pesquisa.

Segundo Klein \& Felippe (1991), a espécie E. heterophyllaapresentou fotoblastismo positivo após ser armazenada por um período de sete meses, porém o que se observou neste trabalho é que tal espécie apresentou germinação indiferente quanto à preferência pela luz, indicando que o tempo de armazenamento pode ter influenciado o fotoblastismo, que, no caso do experimento, foi de dois meses.

A espécie B. plantaginea apresentou germinação indiferente independentemente dos tratamentos realizados, contrariando os resultados apresentados por Freitas et al. (1990), que enfatizaram que tal espécie não necessita de luz para germinar, mas sim de uma escarificação do tegumento.

O efeito da luz é muito questionável, pois cada espécie apresenta um comportamento e, em uma mesma espécie, na mesma planta, há sementes diferentes no que se refere à resposta ao estímulo luminoso (Marcos Filho, 2005).
Portanto, pelos resultados deste trabalho, conclui-se que as espécies de plantas daninhas estudadas - em relação à resposta à presença de luz - são classificadas como fotoblásticas indiferentes, pois germinaram independentemente de receberem os comprimentos de onda na faixa do vermelho $(600$ a $700 \mathrm{~nm}$ ) ou do vermelho distante (730 nm).

Com exceção da espécie E. heterophylla, maior valor foi observado para o índice de velocidade de germinação no tratamento com quebra de dormência, permitindo maior viabilidade das sementes e, conseqüentemente, germinação mais rápida.

De acordo com os resultados obtidos, observou-se que os métodos utilizados para superação de dormência de uma espécie de planta daninha em condições de laboratório são diferentes dos utilizados em condições de campo; portanto, o manejo dessas plantas deve ser realizado com base nos resultados de laboratório, mas com os instrumentos utilizados em campo, englobando os manejos físico, cultural, biológico, mecânico e químico.

Planta Daninha, Viçosa-MG, v. 25, n. 2, p. 303-308, 2007 


\section{AGRADECIMENTOS}

A Francisco Guilhien Gomes Junior, pela colaboração na redação do trabalho, e a Helena Pescarin Chamma, por disponibilizar o laboratório e pelo auxílio na elaboração do trabalho.

\section{LITERATURA CITADA}

AZANIA, A. A. P. et al. Métodos de superação de dormência em sementes de Ipomoea e Merremia. Planta Daninha, v. 21, n. 2, p. 203-209, 2003.

BEWLEY, J. D.; BLACK, M. 2.ed. Seeds: physiology of development and germination. New York: Plenum Press, 1994. $445 \mathrm{p}$.

BEWLEY, J. D. Seed germination and dormancy. Plant Cell, v. 9, n. 7, p. 1055-1066, 1997.

BRASIL. Ministério da Agricultura e Reforma Agrária. Coordenação de Laboratório Vegetal. Regras para análise de sementes. Brasília: 1992. 365 p.

CÍCERO, S. M. Dormência de sementes. In: CÍCERO, S.M.; MARCOS FILHO, J.; SILVA, W. R. (Eds). Atualização em produção de sementes. Campinas: Fundação Cargill, 1986, p. 41-73.

CARVALHO, N. M.; NAKAGAWA, J. Sementes: ciência, tecnologia e produção. Campinas: Fundação Cargill, 1983. 429 p.

EGLEY, G. H. Seed germination in soil: dormancy cycles. In: KIGEL, J.; GALILI, G. (Eds.). Seed development and germination. New York: Marcel Dekker Incorporation, 1995. p. 529-543.

FELIPPE, G. M.; POLO, M. Germinação de ervas invasoras: efeito de luz e escarificação. R. Bras. Bot., v. 6, n. 1, p. 55 $60,1983$.

FLECK, N. G. et al. Efeitos de fontes nitrogenadas e de luz na germinação de sementes de Bidens pilosa e Sida rhombifolia. Planta Daninha, v. 25, n.3, p. 595-600, 2001.

FREITAS, R. R. Dinâmica do banco de sementes em uma comunidade de plantas daninhas com aspectos da germinação e dormência de sementes de capimmarmelada (Brachiaria plantaginea (Link) Hitch). 1990. 117 f. Dissertação (Mestrado em Agronomia) - Escola Superior de Agricultura de Lavras, Lavras, 1990.
FREITAS, R. R. et al. Quebra de dormência e germinação de sementes de capim-marmelada [Brachiaria plantaginea (Link) Hitch]. R. Bras. Fisiol. Veg., v. 2, n. 2, p. 31-35, 1990.

GALLAGHER, R.S.; CARDINA, J. Soil water thresholds for photoinduction of redroot pigweed germination. Weed Sci., v. 45, p. 414- 418, 1997.

GALLAGHER, R. S.; CARDINA, J. Phytocrome-mediated Amaranthus germination. I: Effect of seed burial and germination temperature. Weed Sci., v. 46, p. 48-52, 1998.

HILHORST, H. W. M.; KARSSEN, C. M. Dual effects of light on the gibberelin and nitrate-stimulated seed germination of Sisymbrium officinale and Arabidopsis thaliana. Plant Physiology, v. 86, n. 3, p. 591-597, 1988.

KLEIN, A.; FELIPPE, G. M. Efeito da luz na germinação de sementes de ervas invasoras. Pesq. Agropec. Bras., v. 26, n. 7, p. 955-966, 1991.

LETCHAMO, W.; GOSSELIN, W. A. Light, temperature and duration of storage govern the germination and emergence of Taraxacum officinale seed. J. Hortic. Sci., v.71, p. 373-377, 1996.

MAGUIRE, J. D. Speed of germination-aid in relation evaluation for seedling emergence vigor. Crop Sci., v. 2, n. 2, p. $176-177,1962$.

MARCOS FILHO, J. Fisiologia de sementes de plantas cultivadas. Piracicaba: FEALQ, 2005. 495 p.

NORONHA, A. et al. Photoc ontrol of germination of Cucumis anguria L. Biol. Plant., v. 20, p. 281-286, 1978.

OGUNW ENMO, K.; UGBOROGHO, R. E. Effects of chemical and mechanical scarification on seed germination of five species of Ipomoea (Convolvulacea). B. Society Broteriana, v. 69, p. 147-162, 1999. CD-ROOM.

ROBERTS, E. H. A search for pattern and form. Seed Sci. Res., v. 9, n. 1, p. 181-208, 1999.

TAKAHOSHI, N. Physiology of dormancy. In: MATSUO, T. et al. Science of the rice plant. Tokyo: Food and Agriculture Policy Research Center, 1995. v. 2. p. 45-65. 